\title{
HUMOUR THEORIES AND THE ARCHETYPE OF THE TRICKSTER IN FOLKLORE: AN ANALYTICAL PSYCHOLOGY POINT OF VIEW
}

\author{
Ana Stefanova
}

\begin{abstract}
Humour theories describe different parts of humour as a phenomenon, obtained on the personal and community level, so difficult to be explained. The analytical psychology of Carl Gustav Jung may help in the explanation of why the search for the "Holy Grail of Humour" is as if trying to catch a shadow. The archetype of the trickster in folklore may help us describe some common and different parts of the universal phenomenon of humour and the specific ethnopsychological traits.

The paper presents an overview of basic humour theories, supported by analytical psychology comments, the archetype of the trickster in Bulgarian and Russian folklore, in the folklore of Native American tribes, Kalevala and Edda (Snorri Sturluson) with an attempt to explain how the traits of this "hero" provide a list of the components making something humorous for different people and what are the common traits that can be described as universal.

This overview could help trace the humour phenomenon from the universal, through the community, to the individual level trying to find how important this is in searching for its characteristics.
\end{abstract}

Key words: analytical psychology, archetype, folklore, Holy Grail of humour, humour, humour theories, incongruity, play, profane, relief, sacred, superiority, trickster

For the explanation of the phenomenon of humour we need to involve different approaches, and different sciences. In order to understand the approach of analytical psychology, it is necessary first to review humour theories, created until recently, mostly on the basis of philosophy. In the Internet Encyclopedia of Philosophy, Aaron Smuts (2006) writes about 4 theories:

1. Incongruity Theory is the dominant approach and includes historical figures such as Kant, Kierkegaard, and perhaps has its origins in comments made by Aristotle in Rhetoric. Focusing primarily on the object of humour, this school sees humour as a response to an incongruity, a term broadly used to include ambiguity, logical impossibility, irrelevance, and inappropriateness. 
2. Superiority Theory - according to Thomas Hobbes, humour arises from a "sudden glory" felt when we recognise our supremacy over others. Plato and Aristotle are generally considered superiority theorists, who emphasise the aggressive feelings that fuel humour.

3. Relief Theory is typically associated with Sigmund Freud and Herbert Spencer, who saw humour as fundamentally a way to release or save energy generated by repression.

4. Play Theories attempt to classify humour as a species of play. In this general categorisation effort, the play theorists are not so much listing necessary conditions, as they are asking us to look at humour as an extension of animal play. They try to call our attention to the structural similarities between play contexts and humorous context, suggesting that what might be true of play, might be true of humour as well.

To create a proper definition of humour, different fields of science must be united: philosophy, psychology, sociology, anthropology - social sciences, cognitive science, physiology and medicine, arts, literature, advertisement (management, marketing, commercials) etc. Humour is a phenomenon that we may observe every day in so many different forms, looking so simple and easily cognisable; at the same time it has connections with possibly all aspects of human personality, structures (somatic and mental) and activities which make us humans. The very fact that even the children and, according to some authors, the animals may recognise humour, yet at the same time the difficulty for us, to give an elegant explanation and definition of it, is phenomenal.

When we try to describe humour, it is visible that there are three sides:

1. Character of our response.

2. Properties of the humorous object.

3. What will be sufficient for an object to be found funny - the Holy Grail of humour.

Aaron Smuts writes: "The Holy Grail is often confused with a question regarding the sufficient conditions for our response to count as humorous amusement, but a crucial distinction needs to be made: identifying the conditions of a response is different from the isolating the features something must possess in order to provoke such a response. The first task is much different from suggesting what features are sufficient to provoke a response of humorous amusement. What amounts to a humor response is different from what makes something humorous. The noun (humor) and adjectival (humorous) senses of the term are difficult to keep distinct due to the imprecision of our language in this area." (Smuts 2006) 
But there appears the question - can something be humorous "by itself" what makes something humorous is the question that suggests something to be apart from the human's estimation. However, it cannot exist away from this estimation, living in nature as "humorous" by itself. The human is the one who gives this "label", according to personal and/or collective criteria. The archetype of the trickster is something that best integrates the opposites, being above Good and Evil; something that best fits the idea of "something humorous by itself", because it is universal. According to Paul Radin (1956: x), "Laughter, humour and irony permeate everything Trickster does." The trickster is universal: "Are we dealing here with the workings of the mythopoeic imagination, common to all mankind", the speculum mentis?" (Radin 1956: x).

All humour theories describe different traits and have their meaning.

\section{The concept of C. G. Jung about the psychic structure}

To review humour theories through the standpoint of analytical psychology there are specific concepts that must be defined. According to Jung the psychic structure has conscious and unconscious parts; there is also personal and collective unconscious.

The personal unconscious is about matter that is connected with nationality substances, interjected in early childhood, family, tribe, motherland. Its visualisation in the activities reflects the specific vision and characteristics of the native culture, the spirit of contemporary times, the Shadows. (All that the defensive mechanisms are "hiding" from us but still are ours, our "dark side").

The collective unconscious is the deepest one, "below" the personal, as the deepest "layer" in the structure of the personality, the same in all and everyone, as a pattern. That is why it is universal, because it is identical for all the people (may be in animals, too). The collective unconscious is not dependent on culture, it has its own structure - the archetypes (Jung calls them "organs of the soul"). Its matter has never been in the conscious as it is inherited structure, primordial, that we all are born with. We cannot observe the unconscious directly, but it has a great impact on our personal activities, way of thinking, this is the deep and dark place, where the impulses, instincts, with their imperative way come from.

The archetypes are the tissue, the structure of the unconscious. The interactions among them define the dynamic of the unconscious. They have specific traits and characteristics of interaction among them and the conscious, which actually is the psychic dynamics. They have manifestations in our visible activities, in our thoughts, in the art, folklore, dreams, even in symptoms of diseases. The 
archetypes could be described as different personalities, who lived in our Self, but until the conscious holds the control, the person is psychically healthy. The connection and interactions among the archetypes have a kind of a pattern, framed by our instinctive nature; they are instincts by nature (“...the archetype could be extracted by abstractions of a class of experienced images or objects" (Corsini 1998: 81)).They are "imprints" of the experience of the forbears, not the experience itself, not facts or images, but their mainframe, their essence. The archetypes are connected to the instincts, being numinous, unconscious, autonomic and compulsive. The archetype is a psychosomatic idea that connects the soul and the body, the instinct and the image (Samuels et al. 1995: 38).

We inherit archetypes, they have their own life and personality, but they are also a part of our personality. If they get more energy, they could have the control over the person. The huge variety in material culture is due to the variety of models of creativity of the spirit, having their roots in the archetypal nature. "There are as many archetypes, as typical situations there are in life," writes Jung (1999: 56).

According to Jung, Freud's theory about the libido is partial and unbalanced. In spite of that the concept of the energy has its place in Jung's work. "The neutral nature of the psychic energy means that it may be used everywhere including for searching instruments for reducing the energy tension." (Samuels et al. 1995: 79) These "instruments" could vary a lot - including arts, humour, sport, every kind of activity. "The unconscious is older than the conscious, it is primordial, from it the conscious arises constantly" (Jacobi 2000: 138), thus the conscious "dresses" and guides our actions, but it is impossible for something to appear in the conscious without having roots in the unconscious. The unconscious is the basis; nothing can be developed if it does not have any precursor in the structures before; we cannot really see or understand something if we do not have a primordial archetype or instinct for it as "images" and models for action.

Whatever phenomenon we observe, we must know that there is nothing in the conscious that has not been in the unconscious before. The phenomenon of humour is not an exception in this regard. It is about an instinct, an archetype. Coming from the unconscious, it has an emotional, instinctive nature, the "deepest" layers in our psyche, reducing the energy tension. The conscious may guide and "dress" this instinct, but it could be compulsive if the conscious, the I (Ego) loses control or goes on to "lower" levels (these are the conditions in cases of abusing different substances, stress, mental illness, little children, immature people - all kinds of situations with low control or weakness of the Ego. The conscious is "the connection of psychic content with the Ego, when 
the Ego knows about this", it supports the connection between the unconscious matters and Ego (I, Self) (Samuels et al. 1995: 171).

With regard to its anatomy, the conscious has 4 main structures:

1. Cognitive.

2. Existential-affective.

3. Intentions and will.

4. Reflexive structures.

The cognitive structures act when we first see something, asking the question "what is this?" The existential effectiveness is immediately after them: this is the question "what is the meaning of this object to me?" Everything we get through our senses has emotional estimation for us. There is nothing that we observe, think or have, that has no emotional "colour" for the personality. This is the way our personality works.

Jung's concept describes a universal psychic "layer" and the personal one, dependent on the culture (the group) and the individual, according to his classification of psychological types (a combination among the four functions of conscious, plus intra- and extra-version). This is the way the universal and individual co-exist.

Having these explanations in mind, we can try to reach the very heart of the appearance of the phenomenon of humour.

\section{Humour}

- Always brings pleasure; there is no humour without pleasure for the person, who accepts it as such, bringing quick and easy enjoyment. Not everything about pleasure, fun and entertainment is humorous. Humour can be all of these. Arvo Krikmann (2009) quotes Arthur Graesser, arguing that "recent psychological observations appear to confirm that items of disparaging humour tend to get the highest ratings for funniness."

- It is a form of communication - could be positive (for example "breaking the ice" in a difficult and very serious situation, relaxing the atmosphere) or negative (involuntary or intended sarcasm, mockery, demonstration of superiority). Humour has the potential to bring peace or declare war. According to the linguist Steven Pinker: "The act of communication is based on mutual collaboration between the one who talks and the one who listens. The one who talks sends statement to the listener and implicitly guarantees that the information, which he gives, is relative: it does not repeat the things already known and is connected enough with what the 
listener thinks and may be used for new conclusions with minimum mental effort." (Pinker 2007: 269) From this description we may trace the way humour is dependent on "outer" conditions as an act of communication: 1) the audience - the more prepared it is, the bigger is the effect. Important is the group-effect, the effect of "infection"; 2) the cultural context; 3) the satisfaction of the understanding and the conclusions, to "catch", to get the joke. It should be short, informative, prompt, relative, clear, unambiguous (in cases of incongruity the ambiguity of the communicational act and expression is the "core" of humour, but the understanding should be clear) - these are the traits that the listener expects. Thus, the traits of humour can be described as an act of communication. "The metaphor and humour provide a comfortable way to generalise the two mental actions, which participate in the understanding of a sentence. The ideas are objects, the sentences packing, the communication - sending and receiving." (Pinker 2007: 271)

- As an act of creation (Arthur Koestler's concept about humour, discovery and art): comic collision or oscillation between two frames of reference/worlds of discourse/codes and associative contexts (Krikmann 2009). To demonstrate "good taste" and intelligence - "sophisticated" humour. Aaron Smuts (2006) defines the comic as a professionally produced source of humour, a generic element of various art-forms.

- There can be found similarity within the structures of wits, jokes and dreams. According to Freud, these are products of the primary process, expression of Id. The multiplication and compression are characteristics of the visualisation of the psychic dynamics in dream images. They are also recognisable in jokes, fairy tales and witticisms (in the products of psyche, having unconscious roots).

- Depends on the person's individual traits - such as temperament and psychological type. However, people of different temperament or psychological type obtain humour with different expression, the expression is personally dependent, but its existence is universal.

- Has specific cultural traits, yet there is no culture without humorous traditions or products.

- Could have physiological expression. Humour is somehow connected with laughter - but we can find examples of humour without laughing only bringing positive emotion. At the same time, the reason for laughter could be something very different from humour - jokes, tickling, irony, chemical substances, sometimes as an abnormal reaction - in cases of fear (regres- 
sion as a defending mechanism), sex (in some cultures), even pain (these instances are culturally dependent and of great relevance if we want to go to the very roots of this phenomenon). If we search for an honest scientific approach, the point of view should not be of the "average, white European, with normal intelligence and education". According to Robert Provine, laughter is "a physiological process that results in a limited range of characteristic vocal patterns that are only physiologically possible for bi-pedal creatures with breath control." Laughter because of humour is secondary because it is in response to it.

- There is another important trait - saturation: one joke could not be funny twice or more times; in humour there exists a kind of surprise. If we hear or see something more than twice, it loses "its humorous power". The reaction cannot be so strong any more.

- What is the purpose of the play, we may see in the contribution of observing and learning about the world and ourselves; this is the natural impulse to learn with pleasure that we start feeling at a very early age, as a compulsive need. Humour is very similar to playing. Just like playing, humour is all about observing and exploring the environment. If we search for the purpose, the meaning of humour in life and adaptation, here we may find any basis and similarities. It could be considered as a reaction (active, if it is an act of creation, or passive, if we are only respondents) to the changes in the usual order in the environment that brings us information, quick pleasure and releases energy. Cognition is being involved just as much as emotions (they are inseparable). Krikmann explains the cognitive similarity between metaphor and humour: "Both of these are embodied in texts with dual planes of meaning, both involve a semantic contradiction or incompatibility that the recipient has to disambiguate, using his/her linguistic competence and encyclopaedic knowledge to find some analogy or other "common link" to relate the involved planes of meaning." (Krikmann 2009) This describes the cognitive mechanism for finding "news" and decisions. That is why, connected with "solving problems", humour has a lot in common with riddles, puzzles, wits and also with the language. Because of the emotions involved, humour is estimative. In the process of comparison and disambiguation there is a moment of surprise, observable in riddles, wits, jokes, and in comedies that are funny and "for play". What is needed here is an "intellectual training", a level of cultural integration and education - little children cannot understand thoroughly every act or create cultural products with the purpose to be humorous (it could happen incidentally, but the appreciation comes from adults), but they find other things humor- 
ous, funny. Krikmann quotes Tony Veale about the "the listener as a social agent" and the fact that "the humorous effect arises not because jokes, thanks to their structural properties, force their resolutions on listeners, but because the listener as a social being is predisposed" (Krikmann 2009). This is an extreme "social" and rational position and may not explain if someone finds humorous a product of another culture, being not "prepared" in it or why the children obtain it, too. It does not explain the humour in cases of weakness of the conscious (the conscious is a culture-dependent psyche). This approach puts humour only in the conscious, as an education, in cognitions, not considering its emotional tissue. The psyche cannot act without this component. Yet it is without doubt that personal expectations, connected with the social background, also have their role (often humour arises in exactly such cases of broken expectations). Krikmann quotes Rachel Giora, that "the figurative and humorous items are most enjoyable, if they convey a balanced share of salient and innovative marked information" (Krikmann 2009).

- Has universal basis, i.e. unconscious, archetypal nature. The proof for this is also the common origin of humour along with dreams and creative or cultural products, something expressed in the plots of myths themselves (as it is well known, the mythology is the basis of a way of thinking and belief of the collective kinds of cultures and has its expressions in the individual culture, too). Everything in the behaviour "passes" through the personal traits and culture, but is "powered" by the instincts. All the archetypes as instincts help us adapt better to the environment, they all have evolutionary meaning - for learning (the play), breeding (Anima/Animus), defending (Hero, Wisdom Ghost) etc. According to Radin (1956: x) "as an attempt by man to solve his problems inward and outward, does the figure of Trickster become intelligible and meaningful".

The irrationality, the unconscious, is the worst enemy for the cognitive science in the attempts of making artificial intelligence. The mechanism "if...then" does not make sense. In "humour" we may find the entire palette of emotions: sexual, aggressive, sarcastic, hatred...all these could be humour. Arvo Krikmann writes about political, social, ethnic and obscene (erotic or scatological) themes prevalent in contemporary jokes (Krikmann 2009). He is of the opinion that punch-lines are the basic form of contemporary humour, having functions as social weapon (sounding Marxist) and taboo-breaker (sounding Freudian). This is the way Krikmann explains the "golden era of joke-making" in the former USSR, and he concludes: "despite 
the proliferating cult of sex, joke tradition in contemporary welfare societies is undergoing rapid degeneration" (Krikmann 2009).

The universality is a basis for colourful forms. There is no person or nationality, no culture - contemporary or primitive that has not an attitude to humour. Humour is of compulsive nature, searching ways for expression - a characteristic of the unconscious. The same could be said about music and aesthetics. Creativity and the unconscious origin are the things that they have in common. Even in the simplest object we may see the child or "the savage" making efforts to make it look aesthetic. There is no person who does not have favourite music or who does not like listening to music, even on rare occasions. There is no culture, even primitive, without any kind of music. There are no sufficient conditions to be met in order for something to be "aesthetic" or "music". These phenomena are not directly connected with breeding or surviving. Why do we like them? Yet we are not able to describe what is aesthetic and why. We discharge energy when we communicate with or create any kind of art. Whether we like it or not, depends on the personal and collective level, on universal and specific individual traits. The same goes for "what is humorous". Where to put the borderline, i.e. what makes an "aesthetic" object "a piece of art"? A white ring on black background - is it art? Where does the line exist between tribal drumming and a sophisticated percussion concert (may be the wearing apparel of the listeners and the performance of the "orchestra" in a hall?).

Humour is about vision and hearing and it has no connection to the other senses - olfaction, touch, taste. Nothing that is perceived by way of these three senses could be described as "funny" or humorous. Instead, humour may be found in visual forms, sounds, "intellect" and language, with certain meanings and emotions (coming through the "eyes, ears and mind"). To tickling we may respond with laughter, hence the question - where to put the line between humour and physiological feelings that bring us fun, pleasure and discharge energy with laughter? What amount of something must appear in a situation or in us, or in the environment, to be humorous? According to this review, there is no such a line; the transition from the physiological to intellectual humour is very invisible. The trickster holds both of them and the entire diapason in between. The concept "humour" in Greek means 'juice', 'taste' - in this concept we may find how "fluid" and slippery it is and how much it depends on personal or cultural estimation. It varies in one person in different situations: using substances, creating atmosphere. When we hear laughter, this makes the things funnier; this is a psychological effect - James-Lange theory ${ }^{1}$; humour is contagious. The 
Rizzolatti theory about the mirror-neuron system ${ }^{2}$ also provides explanations in this regard.

- With humour we mark something harmless, but about the "responder". It might not be humorous for the other people. That is why the question about the minimum traits for something to be humorous "by itself" is inappropriate. Someone's grief could be funny for someone else. This is its connection with survival.

Only the trickster's image may "skip" these poles and contradictions, obtaining the characteristics of the numen and the sacral.

- As "responders", there is nothing dangerous or painful about the things we accept as humorous. If the borderline of the situation goes "up", the object is no more humorous, and the fun could be replaced by irritation, fear, anger, aggression - a range of other emotions may appear. It depends on the individual traits of acceptance of the situation and on the permanency of the conditions. The time for reaction is individual, too. For example, if we find someone stupid (superiority) or peculiar, it might seem funny at first, however, if it continues we may feel irritation against this person or situation; other persons or cultures may find it humorous always, etc. Humour and the other possible emotions make a "line" and could "switch" from one to another. In most of its forms humour could be considered as a socially acceptable way for reaction, showing personal maturity, an easy, harmless, cultural way to solve problems, a way to get a "prize" and to "win", taking advantage of a situation, without "going too far". It is also a way to minimise the problem and the importance of a situation, or to manage with a problem. It could also be a form of regression to lower stages of growth and maturity. We may reverse the emotions, after cognitive information, for "retreat": in cases of fear and frightening, when we feel relief and safety, we may react with laughter and/or humour, discharging energy. The situations with "hidden camera" are an example of this: after seeing that it is "unreal" and harmless, the scale of emotions "turns back" and we start laughing. On the other hand, humour may be a reaction of immaturity, rudeness, incorrectness or low control. But there are no sufficient criteria in the object, in the person or in the situation, which help us mark the conditions, in which one "switches" to another. Having in mind the dynamics of emotions, the "level" of humour, once "passed", turns into other emotions - irritation or aggression and it is often hard to be "turned back". A parallel with the physiology of tactile receptors in the skin may be given as an example. One and same agent may cause tickling (itching) (and discharging energy with laughter in many cases), irritation, or pain (discharging with 
scream in some situations). The reaction and the feeling depend on the forces of pressure and the personal threshold for pain. We may clearly see how through the emotions, the quantity turns into quality and the dynamic is between the two contrary poles. The strength of the pressure and the "time amount" of our "exposure" to a humorous act may vary in the scale from pleasure to displeasure (from humour/fun to another emotion). The cultural background, age, temperament, the situation before, and many other factors could be important for the reaction. There are universal and individual components.

Having this in mind, we may conclude that humour (as a psychological dynamic) is both regression and progression: it frames both maturity and immaturity; rational and irrational, emotions and cognitions; it could range from neglecting to overestimation, showing different kinds of expressions (as a reaction to estimation).

In conclusion we may say that humour is based on the anatomy of the conscious, it arises from the unconscious that empowers the actions. Behaviour and activities are visualisation of the human psyche.

If we want to create a humorous product, first we need to consider a "target group" - depending on nation, age, class, sex. Even in this case it would not be funny for all of the audience. A reason-consequence law about something to be humorous cannot be dismissed, as it is to do with something irrational and depends on many factors. The same situation is observable with the concept of "aesthetic". If we observe cultural evolution from the tribal level to nowadays, we will see how the sacred and the profane have changed in their expressions. In the tribal cultures the role of humour is very important for the community and its healing power is embedded in the human psyche. Being sacred has many aspects; it is multidimensional, having the characteristics of numen. This proves the archetypal, instinctive nature of humour. In other products of human activity (e.g. in folklore), humour is also embedded in stories with a moral, to teach the youth. As a way for revenge, for example, the small and the poor outwit the big and rich - this is a way for discharging negative emotions, envy and a way to take advantage over someone, in front of whom one feels helpless. It has integrative, educative, entertaining, therapeutic, estimative, communicative, self-expressive roles.

The collective unconscious is universal, probably also including the animals, writes Jolande Jacoby (2000). Play theories often take an ethological approach to studying humour, tracing it back through evolutionary development. These theories and the situations of conscious suppression (weakness) give information about the roots of some phenomena (humour in this case) and the interaction 
between the conscious and unconscious. Aaron Smuts writes: "They look at laughter triggers like tickling, that are found in other species, to suggest that in humour ontogeny recapitulates phylogeny. In The Enjoyment of Laughter, Max Eastman develops a play theory of humour with an adaptive story. He thinks we can find analogies of humour in the behaviour of animals, especially in the proto-laughter of chimps to tickling. He goes so far as to argue that the wagging tail of a happy dog is a form of humorous laughter." (Smuts 2006) By definition, the conscious is a culturally created and determined kind of psyche. It means that only mature, psychically healthy persons obtain the conscious. But the preposition for humour lays in the unconscious. Do retarded people or people with mental diseases enjoy humour? Yes, because it is empowered by the unconscious, the conscious only gives a "form". What is perceived to be humorous in a normal situation differs from that under the effect of different substances. In the latter case even an apple may seem to be funny, whereas in a "normal" situation, the same person would not think it to be humorous at all. However, humour cannot be explained by way of biochemistry regarding the metabolism of the used substances (e.g. when using LSD), because in the same situation, under the same conditions, the reaction of this person may vary from laughter to fear or panic attack, while under the effect of one and same substance (moreover, the emotions in such a condition could move from one extreme to another). Likewise, the "background" is important, too. When the person is suppressed, in stress, tired, in a dark mood, or not interested, the threshold for something to appear to be humorous is higher, so there are stronger stimuli needed to activate the relevant reaction. In such cases the emotions are suppressed. When consciousness is weakened, emotions arise more easily and powerfully.

The "holding back impulse" of immediately discharging, according to Freud, ensures longer and bigger pleasure - the sophisticated and intellectual kind of humour could be observed in the situations of a good control and "higher" conditions of the conscious, when cognitive functions work well. Such humour is a product of conscious awareness and creativity, and is a kind of art.

All these facts support the thesis that humour has roots in the instinct, in the deepest "layers" of our psychic structure. The archetype expresses the attempt to find a way to release energy in the behaviour, in the activities. How much it "takes" from the conscious depends on many factors, at personal and collective level, and the border is conditional and conventional. Yet all these factors are rooted in the universal unconscious; they originate from this one ubiquitous source, equal for all. "Touching" the conscious and the outer environment, it "meets" conditions that form its face and traits. 
In The Language Instinct Steven Pinker defines the "d-structures - everything, which is hidden, universal, deep or meaningful - they are about the visual perceptions, like narratives, myths, poems, pictures, musical compositions etc. (Noam Chomsky defines this in the sixties of the 20th century). D-structures are the interface between the mental dictionary and typesetting (compositor's) structure." (Pinker 2007: 136) The nature and the structure of the language are in deep connection with the psyche. It is a life form of the psyche and also a construction material for different psychical phenomena, which "are dressed" in the language.

Pinker explains that we do not think in words, arguing that the language does not come from the conscious. He uses the term mindlect when referring to the d-structures. These intuitive structures are on the level of the primal process (Freud's concept) and if we "translate" the product to the level of the secondary process, we have a logical and tidy explanation, but the humorous part disappears (only cognitions play a role in this "translation", escaping the emotions). On the secondary process level, the humour is dead. Very often we may find something humorous, when just seeing it, and if we try to put it in words, the "magic" disappears. In humour, as in language, there is a deep, irrational part which comes from the unconscious and fills the product with these phenomena, giving them life and power.

According to Pinker the mindlect helps us, giving "labels when we see something and guess about its characteristics, which are not immediately visible. In this case we use the traits that we can see as a basis" (Pinker 2007: 179). When we have a "humorous experience", we see traits that the culture and/ or our background experience and personal characteristics "recognise" as humorous. It is compulsive, but in most cases there is a moment of "education" about what is funny. Once "labelled", on a cultural, community level, we are already prepared on a personal level to act in a specific way. The child from early age, subject to a certain culture, begins with more "physiological" samples of humour (cartoons, jokes, etc.), and passing through the process of becoming familiar with the cultural patterns, he/she gets to a certain level, depending on his/her personality, education, experience and cultural background. Pinker (2007: 180) describes experimental testing on babies evidencing that they can recognise objects and activities, even before they know the words which denote these objects. This is another supportive argument underlying that the drive for humour is away from words and activities. The "labelling" has yet another function - it helps "holding back" the release of energy for a shorter or longer period of time, according to Freud, thus causing additional and longer pleasure. (The process of thinking, evolving with the age, is also connected with holding 
the impulse for immediate discharging. This delay develops in thinking, according to Rapaport (Brenner 1993: 44)).

Pinker argues that the deliberated violation of the unwritten norms of communication activates some forms of non-literal language, such as irony, humour, metaphor, sarcasm, wits, rhetoric, biting remarks, persuasion and poetry (Pinker 2007: 270). So, the conditions cannot be placed only in person, in the environment or in the object. They are in variable combination, but the main is the instinct, the congenital need for making and accepting humour - what is "seen" and what is "heard" as humorous is in the language of the primal process, connected with the experiencing of a symbol (according to Jung, the symbol always says more than we see, it is unlimited). Humour may be found in and created by the language.

Arvo Krikmann discusses the relationship between verbal humour and figurative speech, describing cognitive similarity. He finds it difficult to devise clear-cut theoretical criteria to distinguish between the two. Reviewing the concepts of other scholars, he outlines the metaphor as a violation of certain rules, schemas, frames, isotopes, involved in both metaphor and punch-line jokes; the perception of both funniness and figurativeness. Krikmann argues that the "awakening" of metaphors, idioms and "decomposing" of compound word (via translating or otherwise) are largely exploited techniques of humour making, similarly to the parodying of proverbs, and also the blends thereof, which "quite obviously appear to have a strong natural capacity to feed fantasy and produce humour"; "jokes can be based on the literalising, extending, twisting or mixing of metaphors" (Krikmann 2009). Also, nonsensical words could be divided into simply nonsense and funny nonsense. According to Krikmann (2009) "it does not allow us to distinguish more precisely which violations of maxims will simply result as communicative errors, which ones as units of figurative speech, and which ones as humorous items." The analyses so far, according to Krikmann, "do not aim to tell us more exactly which blends do result in humour and which ones do not" (Krikmann 2009). Once again, it is visible that sufficient conditions are not easy to be brought out. The sufficient conditions cannot be found even in the character of the trickster: "Yet it is difficult to say whether the audience is laughing at him, at the tricks he plays on others, or at the implications his behaviour and activities have for them." (Radin 1956: x) 


\section{The sacred and the profane}

According to Jung the primary readiness to believe in transcendental forces, is a premise for the experience of the numinous. The definition that Samuels et al. give about "numinous" is: "A characteristic of a tangible object or impact of intangible presence, which causes a specific change of the conscious. It is unexplainable, but it seems it transfers a kind of individual message, which is mysterious, secret and deeply impressive." (Samuels et al. 1995: 11-112) The numinous cannot be overcome; one can only open himself for it. The archetype has numinous and sacred traits. Mircea Eliade (2000) states that the Sacred is universal and the beginnings in cultures originate from religious experiences and beliefs. He also argues that the dialectics in the Sacred precedes and is a pattern for every dialectic movement, discovered by the mind later. The experience of the Sacred by unveiling the being, the meaning and the truth in an unknown, chaotic and frightening world prepares the way for systematic thinking. The Sacral is an element of the structure of mind; it is not a stage in its history (Eliade 2000). Bearing in mind these conclusions we may review the trickster's images and their "evolution" in different cultures and in time. Eliade describes how very important it is to review a fact not only with regard to its historical, socio-cultural, linguistic, context, but also in its "spiritual" essence and meaning, i.e. "the dimension creates the phenomenon". That is why the description of archetypes is so important - to reach the deep, unconscious, universal matrix and its dynamic, always connected with the conscious and outer conditions, which gives the "community" vision in folklore. Humour which is an option of the mind has sacred and profane traits in a certain balance, changeable in time and space.

Jung describes the archetypes, the traits and dynamics of which are observable in myths, folklore, products of creation, dreams, and can be symptoms of disease.

The archetype of the trickster is the one, opposing the traits of the funny/ humorous/bad/tricky hero with all the sacred and controversial traits in unity. The trickster is a part of almost all the cultures in the world, he is universal. The trickster could be not only male but female, too. This character is the "interface", leading from the universal unconscious to the specific "outer" expression - the products of humour. "He wills nothing consciously" writes Radin, describing the trickster's origin and dynamics. The trickster keeps us from being too confident in ourselves, in our point of view, argues Susan Wyatt (2005). According to her, it is an advantage to be a trickster. He is an inventor of many cultural achievements (fire-making, the lyre, the www, railways (communication), etc. - that proves the creative aspects of humour). However, he is also a de-constructor, 
breaking the rules is his way to find new horizons (the same aspect of "breaking rules" is visible in humour-making methods); finding and bringing knowledge is yet another aspect of humour. The trickster gives us the possibility to experience the paradox; he delights in the "auspicious bewilderment" (Anderson 1998: 84). He refuses the oppression of the spirit - a thing that humour does. Susan Wyatt (2005) describes him as a charmer and enchanter, transformer of reality searching for multiple of possibilities of meaning - these are the traits used by people to describe those who obtain and react with humour. The trickster is skilful with language - the connection between humour and language is undeniable. He provokes insight and awakens energy (Wyatt 2005) - exactly as humour does. The image of the "funny" hero in folklore is very representative of humour (with its own specific psychological traits) in the regions and countries, where the trickster "gets his outer form".

This archetype is about the carnival, about the turning upside down, associated with many rituals (Jung 1956). This is Heyoka from the Native American folklore, the medicine man, the shaman who heals the tribe, always behaves on the contrary to the situation, yet obtains the biggest power compared to all other kinds of shamans. The awakening of his powers is summoned by lightning, by the Thunderbirds in his dreams. In the image of this archetype we could find the grotesque, the chaos, the lie, the demonic, the ugly, revenge, damage, harm and mischief. The character is ambiguous, obtaining also Wisdom, the Sacred in Unity. The trickster (the jester) is the only one allowed to tell the truth to the King, he is the best singer and poet, but often neglected and contemptible. The jester is intuitive, intelligent and clever. He combines prompt truth and the grotesque expression. Trickster stories reveal in "gleeful insubordination" (McNeely 1996: 87). This is closely connected with his divine function, to mediate the worlds.

Diabolic vision is also related to the trickster. The contemporary man likes to keep away from the trickster in ordinary life. But not one of the archetypes can be cut away from the soul. The archetype is "an everlasting presence and the question is only in that: do the conscious accept it or not" (Jacobi 2000: 62).

This archetype is the closest idea to what the Holy Grail of Humour searches for. Being above Good and Evil, ambiguous and whole, this image excludes the pros and cons and is a complete idea. "He has no control. He knows neither good nor evil yet he is responsible for both" (Radin 1956: ix).

The trickster in the culture of Native American tribes is widely spread. In this culture he is presented in his "earliest and most archaic form" (Radin 1956: ix). The Zuni have sacred clowns Koshare (Pueblo clowns), performing during the spring and summer fertility rites. Among the Hopi there are five figures who serve as clowns: the Payakyamu, the Koshare (or Koyaala or Hano 
clown), the Tsuku, the Tatsiqto (or Koyemshi or Mudhead) and the Kwikwilyak. With the exception of the Koshare, each is a kachinam or personification of a spirit. It is believed that when a member of a kiva wears the mask of a kachinam, he abandons his personality and becomes possessed by the spirit. Each figure performs a set role within the religious ceremonies; often their behaviour is comic, lewd, scatological, eccentric and alarming. They dance between the different parts of serious sacred ceremonies, saying funny, ridiculous, rude jokes to some people of the audience. Their behaviour is ridiculous copying of the solemnity. This is a responsible and sacred occupation, not an antithesis of the official ceremony, but an important part thereof. The Mica (Coyote) and Iktomi (the spider-trickster spirit in Lakota mythology) are other trickster-heroes. There is a lot of sexuality, cunning, tricky ways of acting and solving situations. The sacredness connects these traits with a "higher" principal - fertility, wellness, joy, a certain order in the Cosmos, above the profane. In trickster's actions we may observe clear examples of all the basic humour theories: superiority, incongruity, play and relief. The sacred and the profane are closely connected, the character is ambiguous.

Particularly in the "primitive" cultures can we find the essential role of this phenomenon, and the sacred aspect that comes from this archetype proves the irrational nature of humour, originating in the collective unconscious (along with creativity, dreams and symptoms). All other attributes come "in addition", specific for space, time and individual.

The mythological description of Iktomi, the spider-trickster spirit, unveils some important traits that may show how humour is connected with life, what do people accept and how do they do this, what is its meaning and importance. Iktomi is the son of the rock, the creator god. His brother is a destructive and powerful spirit. Once Iktomi was Wisdom, but was stripped of the title because of his troublemaking ways. His malicious plans very often failed, so these tales were usually told as a way to teach lessons to Lakota youth. Iktomi gives the dream-catcher to people. Folk tales unveil how he is respected, feared and mocked. A lot of traits entangle in this hero and all the aspects describe the attitude to the sacred phenomenon of humour in tribal cultures. In collective cultures, in the mythological way of thinking, it is better visible. The opposites are reconciled, this is one of the relevant traits - here we see how evil and good, funny and wise are one, having a supreme power and being servant at the same time. Iktomi is a shape-shifter. He can use strings to control humans like puppets. He also has the power to make potions that change gods, gain control over people and trick gods and mortals. According to a prophecy Iktomi would spread his web over the land. Today, this has been interpreted by some contemporary Native Americans to mean the telephone network, and then the 
Internet - the world-wide web. Iktomi has been considered by Lakota from time immemorial to be the patron of new technology, from his invention of language he gave to the people, to today's modern inventions, such as the computer or robots. The myth is a way for the psyche to talk about itself, according to Jung. These models and ideas, that the folklore narratives give, point to the roots of humour from the unconscious, accompanied by creativity/inventions, language, communication and dreams (dream-catcher) as gifts from one and same character. In the phenomenon of humour we may see its manifestation and similarity in all these, proving the unconscious origin of all (language, humour, dreams). Iktomi is also connected with games and playing, with music and pleasure, just like humour. This is how the mythological basis may give information for the components and the traits of the archetypes. Many Lakota today consider Iktomi to be the god of the Europeans, who (they claim) seem to readily follow his (to them) bizarre behaviour and self-entrapping tricks. This is a kind of projection of unassimilated psychic substances over something "foreign", experiencing them as an "outer" part. This shows the process of splitting in the unity of the character, marking a process of transformation from collective into an individual kind of culture.

Coyote is Iktomi's great accomplice in all of this, though there are times when he behaves seriously and comes to the aid of the Lakota people, there are instances where he gives the people ways to protect from evil, live a better life with technology, or warn them of danger. The European equivalent is the Fox. He rises against the restrictions (just like the Id, according to the psychoanalytical theory), against the authority, he is everything that the "descent" and conform person secretly wants to be: mischief and hero and the one who brings progress as clown and maker. In most of the stories and interpretation he is immortal. There are some tales, in which he made people from wood or clay, invoking life with his breath; he is a Demiurge. He behaves as a normal person, too; there are funny stories with a sexual kind of humour, where he acts as a normal man, in profane situations. The sacred accompanies all tribal life. In one and same story he appears as greedy and lusty, but also as a grateful and heeling medicine man (healing the blind for example) and is "the one who always lives at the shore" (Erdoes \& Ortiz 2005: 548). The Great Secret Power created Coyote; in some stories this Power is very wise and likes joking and fun. The Great Secret Power protects him, because of his funny behaviour. The same way as the Ego appreciates humour and Superego makes restrictions (according to the psychoanalytical theory).

The thin line between fun and stupidity, between harmless and dangerous is described with the four lives that the Power gives to Coyote ("Coyote dances with a star" in Erdoes \& Ortiz 2005: 584) to protect him from his own stupidity. 
By nature the Power is generous, with a sense of humour, wise, but appreciates entertainment and diversity. The trickster is a part of that Power (the Self, according to the analytical psychology concept), an integrated subject thereof.

It is very important to mark the meaning of and the attitude towards these characters. The community gave them the name Wisdom. In peoples' expectations Iktomi created a huge amazing invention as the dream-catcher, and the world-wide-web could be considered to be the most recent "equivalent" of this, as mentioned above. Iktomi is creative, wise, but at the same time bad, envious, greedy and ambiguous. All this makes him sacred, because in such societies (collective cultures), the concepts are closer to their archetypal meaning.

The Algonquin story, "Gluskap Fulfils Three Wishes" (Erdoes \& Ortiz 2005: $553)$, is about the tribe from the "savage" times, searching to find the funny sounds from the body. Yet there is an indication that recently this has changed. In the same story the young man, with the help of Gluskap, obtains the possibility for making such sounds, because he wants to be funny for the others. At first the tribe finds this very amusing, but quite soon no one wants to listen to the sounds any more. This folklore tale allows for diachronic observations and enables to see the sequence of emotional changes - how irritation replaces humour, when it lasts too long. It also tells how something, funny for some, could be disgusting for others; how, in the course of time, the criteria for humour change - in the community and in a single individual. Folklore facilitates the research in time, space, and of us ourselves.

There are other trickster images in Native American folklore - different animals - the Rabbit, the Raven, who possess magical powers and are extremely cunning. However, "basically he possesses no well-defined and fixed form" (Radin 1956: x). Being a shape-shifter, the trickster is just like "humour" (liquid), escapable.

Richard Erdoes is a co-author of a biographic book about the famous shaman from Sioux Lakota, Lame Deer (Erdoes \& Lame Deer 1999). This was not only about his shamanic "career", but his personal life as a trickster, full of adventure and ambiguity (as "morality" according to the wide-spread belief in the collective conscious principles), but not contradictory. Lame Deer is an example of successful unity and harmony. This is how the close connection with the archetype works, giving the opportunity for integration and reaching the Self.

The trickster, as an archetype, lives in every one of us, he is a universal image and rises against the archetype of Persona. His sacred creativity is better visible in ancient stories, where the moral is less important. He brings the vital powers of Chaos, introducing the new, not understandable, the wired, and the progress. 
The completeness of the character may be seen only if searching for its different expressions on the basis of the universal archetype. For instance, the connection with death and unity, that frame the traits of continuation and immortality, is especially well developed in the voodoo culture (Metro 2004). There the trickster images, loa Guédé (Baron Samedi etc.), spirits of the dead, reveal another side of the archetype, giving an idea for its multi-dimensional nature that explains well the feeling for numinous, sacred and mystery. Loa Guédé being promiscuous, their language is full of blasphemy, and their behaviour is scatological and erotic. These are characteristics of humour, but in a generalised line they lead to the sacred concept of fertility. In the same character Fertility is united with the Death - two opposites, which make the trickster ambiguous, but are whole and why this brings the experience of numinous.

In Snorra-Edda there is also a trickster image in the pantheon of gods: this is Loki. He helps the gods, but sometimes makes trouble. He is a shape-shifter, and has a role to play in Balder's death.

We may also find the trickster's traits not only in mythology but also in the "Story of Shuttle-Halli", "Story of Hreidar", etc. Here the trickster loses his "holiness", but is respected, adaptive and survives. The trickster-hero is a legendary character. He may turn every situation to his own advantage and win even in the most severe circumstances. There is no assessment of good or bad, the hero is above them. This is because the ambiguity, which only brings the person to reach the Self, obtaining the Manna-traits (giving possibilities for individuation, opportunity for connection between the worlds, between the sacred and profane). The story gives the feeling that all people, even the enemy, admire him; irrespective of the deeds, the winner is always right. These traits are about the integrative, adaptive aspects of the trickster archetype.

In Kalevala Lemminkäinen is a shamanistic figure. He is an epic hero, but also a trickster's trait bearer. He is a kind of a super-human person; his body is recovered (according to Eliade - a shamanistic skill for initiation) thanks to his mother's prayers and magic. He is not a god, but has supernatural skills. He makes mistakes; very often he shows disobedience in a very funny way, frivolous and rushing, with great self-confidence. Singing loudly and out of tune, not at the right time and place, he becomes the reason for ruining the mission of his friends, but is also good company and a brave hero. Here we see this image still in the group of mythical and sacral.

In the age of Christianity humour is not God's attribute anymore. We may see a clear division in the trickster's image, becoming a Devil's or Satan's characteristic. This marks the beginning of splitting the unity, because in late Christian culture Satan and Christ are not equal members in the Heavenly Pantheon. The ambiguity is apart, in divergence. The trickster's traits are 
reduced and shown with a small range: stupidity, chaos, cruelty, anger, cunning, trouble-making, mischief or misunderstanding, but without the opposite traits (wisdom, healing opportunities, creativeness etc.) in one and the same character. According to Susan Wyatt (2005), it is difficult for the trickster to thrive in a monotheistic world. He could be found in contemporary mythology, too (for example the character of Jack Sparrow in the "Pirates of the Caribbean").

There are some animals in European Christian cultures, bearers of trickster's traits; they are close to the Devil, his familiars or bearing a similar appearance: the Wolf, the Fox, the Raven. Christianity separates the symbols, creates dualism in folklore, in ideas in general. There is a certain negative attitude to those "dark" fellows, the ambiguity and sacral moments, well visible in pagan cultures, are missing. Some pagan traits or plots are imprinted in folklore expression, but the sign and modification of Christianity is very clear.

The national hero-tricksters in Bulgarian and Russian folklore are peasants and the sacral traits are missing. All their activity is aimed at better adaptation, to win an advantage, very often - material acquisitions and prosperity. The character is mostly rational. This is the image of Hitar Petar (The Cunning Petar) in Bulgarian folklore tales. The Devil and the Wolf are also tricksters, having very similar traits in Bulgarian folklore (non-symmetrical, belonging "here" and beyond, ambiguous). They could be either "light-bearers" or "light-eaters".

In Russian folklore this is the image of Ivan the Fool. The profanity of the sacral is visible, but there exists also another element: a kind of a destiny involvement, supernatural luck, Guiding Force, blessing and protective (like the Native American story "Coyote Dances with a Star"). Yet here, this Force is nameless; not explained as a God's will or any other kind of Power. It is helping, forgiving stupidity, appreciating good heart and funny acting. Ivan the Fool is not cunning, like the trickster in Bulgarian folklore. Very often his deeds are just the contrary, putting him into trouble. This nameless Force in the plot takes part in the moral of the story, it is like a conclusion, that this Power exists, protecting the good and funny, and is the "bridge" that welds together the split opposites, bringing back the unity. The sacral feeling is missing, the numen is gone; these stories, being just tales are either entertaining or have an "educational" meaning to the youth (in both ways "do just like Him if you want to win", or "don't fool yourself like Him"). But they are never a subject to healing performance for the community in the way the myth-based narratives were performed in other cultures and times. The sacral experience of the community, the mystery and the ritual are away. The power, the meaning and the importance of the tales and their connection to the myth (through the archetype) is not a subject of this paper. 
The specific traits on a community level put an imprint on personal experience and performing of humour, and on other community phenomena. It is well observable how the instinctive, personal impulses took shape; they form under the pressure of the collective factors and find specific expressions, certain symbolic forms and plots in the folklore. We can see how the meaning changes in time, altering the sacral traits as much as it comes away from the "pattern" of the archetype, forming a part of the individual kinds of culture.

The question about the traits and minimum conditions for something to be humorous should not be asked partially and only from the "outer", descriptive side, without considering the universal phenomenon of the driving instincts, the archetypal nature as a powered impulse. The question should not be asked about a typical average person, culture, time or community.

Exactly as in the myth, the Holy Grail is an archetype - literally. The archetype of the trickster obtains the idea of the unity of opposites, the experience for humour above Good and Evil, on a high, or more exactly "low", basic level. That is why this experience has numinous traits - because of the multidimensional nature of Unity (in the ambiguity) that the archetype obtains. It really exists, but has different vision, appearing "through" the conscious; we cannot push it in one form or definition, but we experience its heavenly sacred and/or desacralised substance (depending on the personal and collective level and difference in time). As everywhere in science, when we ask a question, the answer always begins with "It depends on..." 


\section{NOTES}

1 "The more I cry, the sadder I become." The physiological impulses from the body are reason for psychic reaction and condition.

${ }^{2}$ Giacomo Rizzolatti and Laila Craighero (2004). The mirror-neurons help us understand the behaviour of the others and also "do" the same we see or hear, on a "virtual", subliminal level.

\section{REFERENCES}

Anderson, Rosemarie. 1998. Intuitive Inquiry: A Transpersonal Approach. In: W. Braud \& R. Anderson (eds.) Transpersonal Research Methods for the Social Sciences: Honoring Human Experience. Thousand Oaks, CA: Sage.

Brenner, Charles 1993. Psikhoanaliza. Osnoven kurs. [An Elementary Textbook of Psychoanalysis.] Sofia: Fondatsiia "Otvoreno obshchestvo".

Corsini, Raymond 1998. Entsiklopediia psikhologiia. [Encyclopaedia of Psychology.] Sofia: Nauka i izkustvo.

Eliade, Mircea 2000. Tarseneto. Istoriia $i$ smisal v religiiata. [A History of Religious Ideas] Sofia: Izdatelstvo Lik.

Erdoes, Richard \& Ortiz, Alfonso 2005. Mitove i legendi na severnoamerikanskite indiantsi. [American Indian Myths and Legends.] Sofia: Iztok-Zapad.

Erdoes, Richard \& Lame Deer, John (Fire) 1999. Kutsiia Elen. Tarsach na videniia. [Lame Deer, Seeker of Visions.] Sofia: Shambala.

Jacobi, Jolande 2000. Psikhologiiata na K. G. Jung. [The Psychology of C. G. Jung.] Pleven: Lege Artis, pp. 18, 62, 138.

Jung, Carl Gustav 1956. On the Psychology of the Trickster Figure. In: P. Radin The Trickster: A Study in American Indian Mythology. New York: Schocken.

Jung, Carl Gustav 1999. Arkhetipite i kolektivnoto nesaznavano. [Archetypes of Collective Unconscious.] Pleven: EA, p. 56.

Krikmann, Arvo. 2009: On the Similarity and Distinguishability of Humour and Figurative Speech. Trames: A Journal of the Humanities and Social Sciences, Vol. 13 (63/58), No. 1, pp. 14-40. Also available at http://www.kirj.ee/public/trames_ pdf/2009/issue_1/trames-2009-1-14-40.pdf, last accessed on 30 March 2012.

McNeely, Deldon Anne 1996. Mercury Rising: Women, Evil and the Trickster Gods. Woodstock, CT: Spring.

Metro, Alfred 2004. Kultat vudu v Khaiti. [Voodoo Cult in Haiti.] Sofia: Lik.

Pinker, Steven 2007. Ezikoviiat instinkt. [The Language Instinct.] Sofia: Iztok-Zapad, pp. 136, 175, 179, 269-277.

Radin, Paul 1956. The Trickster: A Study in American Indian Mythology. New York: Schocken.

Rizzolatti, Giacomo \& Craighero, Laila 2004. The Mirror-Neuron System. Annual Review of Neuroscience, Vol. 27, pp. 169-192. 
Samuels, Andrew \& Shorter, Bani \& Plaut, Fred 1995. Kriticheski rechnik na analitichnata psikhologiia na K. G. Jung. [A Critical Dictionary of Jungian Analysis.] Pleven: EA, pp. 38, 79, 171.

Smuts, Aaron 2006. Humor. Internet Encyclopedia of Philosophy, http://www.iep.utm. edu/h/humor.htm, last accessed on 30 March 2012.

Wyatt, Susan 2005. Awakening the Trickster. The First International Congress of Qualitative Inquiry, May 5-7, http://www.iiqi.org/C4QI/httpdocs/qi2005/papers/wyatt3. pdf, last accessed on 30 March 2012. 